\title{
Assessment of adherence to the guidelines for the management of nausea and vomiting induced by chemotherapy
}

\author{
Avaliação da aderência à diretriz de cuidados para náuseas e vômitos \\ induzidos por quimioterapia \\ Monique Sedlmaier França ${ }^{1}$, Pedro Luiz Serrano Usón Junior ${ }^{1}$, Yuri Philippe Pimentel Vieira Antunes ${ }^{1}$, \\ Bernard Lobato Prado ${ }^{1}$, Carlos del Cistia Donnarumma ${ }^{1}$, Taciana Sousa Mutão ${ }^{1}$, \\ Heloisa Veasey Rodrigues ${ }^{1}$, Auro del Giglio ${ }^{2}$
}

\begin{abstract}
Objective: To assess adherence of the prescribing physicians in a private cancer care center to the American Society of Clinical Oncology guideline for antiemetic prophylaxis, in the first cycle of antineoplastic chemotherapy. Methods: A total of 139 chemotherapy regimens, of 105 patients, were evaluated retrospectively from 2011 to 2013. Results: We observed $78 \%$ of non-adherence to the guideline rate. The main disagreements with the directive were the prescription of higher doses of dexamethasone and excessive use of 5-HT3 antagonist for low risk emetogenic chemotherapy regimens. On univariate analysis, hematological malignancies $(p=0.005)$, the use of two or more chemotherapy $(p=0.05)$ and high emetogenic risk regimes $(p=0.012)$ were factors statistically associated with greater adherence to guidelines. Treatment based on paclitaxel was the only significant risk factor for non-adherence $(p=0.02)$. By multivariate analysis, the chemotherapy of high emetogenic risk most correlated with adherence to guideline $(p=0.05)$. Conclusion: We concluded that the adherence to guidelines is greater if the chemotherapy regime has high emetogenic risk. Educational efforts should focus more intensely on the management of chemotherapy regimens with low and moderate emetogenic potential. Perhaps the development of a computer generated reminder may improve the adherence to guidelines.
\end{abstract}

Keywords: Nausea/chemically induced; Vomiting/chemically induced; Clinical protocols; Advance directive adherence; Drug therapy/adverse effects; Antiemetics

\section{RESUMO}

Objetivo: Avaliar a adesão dos médicos prescritores, de um centro privado especializado em oncologia, à diretriz de antiêmese profilática da
American Society of Clinical Oncology, no primeiro ciclo de quimioterapia antineoplásica. Métodos: Foram avaliados retrospectivamente 139 esquemas de quimioterapia, de 105 pacientes, tratados no período de 2011 a 2013. Resultados: Foram observados 78\% de taxa de não adesão à diretriz. As principais discordâncias com a diretriz foram prescrição de doses mais elevadas de dexametasona e uso excessivo de antagonista 5-HT3 para regimes de quimioterapia de risco emetogênico baixo. Pela análise univariada, malignidades hematológicas $(p=0,005)$, uso de dois ou mais quimioterápicos $(p=0,05)$ e regimes de alto risco emetogênico $(p=0,012)$ foram fatores estatisticamente associados a maior adesão à diretriz. 0 tratamento baseado em paclitaxel foi 0 único fator estatisticamente significativo para a não adesão $(p=0,02)$. Pela análise multivariada, a quimioterapia de alto risco emetogênico apresentou maior correlação com a adesão à diretriz $(p=0,05)$. Conclusão: Houve maior aderência para a quimioterapia de alto risco emetogênico. Esforços educacionais devem se concentrar mais intensamente na gestão de regimes de quimioterapia com potencial emetogênico baixo e moderado. Talvez o desenvolvimento de lembretes gerados por sistemas informatizados possa melhorar a aderência à diretriz.

Descritores: Náusea/induzido quimicamente; Vômito/induzido quimicamente, Protocolos clínicos; Adesão a diretivas antecipadas; Quimioterapia/efeitos adversos; Antieméticos

\section{INTRODUCTION}

Clinical support is essential in the fight against cancer. Much of the stigma related to malignant neoplasms is due to the side effects of the treatment, particularly nausea and uncontrollable vomiting. ${ }^{(1)}$ Proper management of

\footnotetext{
'Hospital Israelita Albert Einstein, São Paulo, SP, Brazil.

2 Faculdade de Medicina do ABC, Santo André, SP, Brazil.

Corresponding author: Monique Sedlmaier França - Avenida Albert Einstein, 627/701, building A, 3rd ss - Morumbi - Zip code: $05651-900$ - São Paulo, SP, Brazil - Phone: (55 11) 2151-1233 E-mail: falecommonique@hotmail.com

Received on: Mar 26, 2014 - Accepted on: Apr 24, 2015

Conflict of interest: none.

DOI: 10.1590/\$1679-45082015A03097
} 
these symptoms enables improved quality of life and greater adherence to cancer treatment. ${ }^{(1,2)}$

Over time, various medications have been developed to prevent the nausea and vomiting associated with chemotherapy. ${ }^{(3)}$ The three main classes of drugs used for this purpose are glucocorticoids, 5-hydroxytryptamine (5-HT3) receptor antagonists, and neurokinin 1 (NK-1) receptor antagonists. ${ }^{(3)}$ As these medications are not devoid of side effects and many of them are high cost drugs, their use must be rational and based on the best scientific evidence.

In 1997, a stratification of the emetogenic potential levels of chemotherapeutic agents, alone or in combination, was proposed.(3) More recently, in 2011, Grunberg et al. ${ }^{(4)}$ updated the classification and divided the chemotherapeutic agents into four emetogenic potential levels: high, moderate, low, or minimal. Based on this proposal, recommendations were developed to standardize the prophylactical use of antiemetics. ${ }^{(5-7)}$

\section{OBJECTIVE}

To assess adherence of the prescribing physicians in a private cancer care center to the American Society of Clinical Oncology (ASCO) guideline for antiemetic prophylaxis, in the first cycle of antineoplastic chemotherapy. Then, to characterize the differences between the procedures suggested by the guideline and those performed in clinical practice, and to evaluate the factors that contributed to adherence or non-adherence to protocols.

\section{METHODS}

This was a retrospective and descriptive study, in which we collected data on the prescribed medications during the first cycle of chemotherapy, for patients who underwent chemotherapy between September 2011 and February 2013, in the inpatient units and the outpatient chemotherapy sector of the Hospital Israelita Albert Einstein. Patients aged 18 or older, who received cancer treatment for both hematologic and solid malignancies, were enrolled consecutively. All the initial cycles of patients who underwent more than one line of chemotherapy during the period were included and analyzed, because the guideline used was published in 2011. We excluded patients with insufficient information about the treatment, patients in concomitant chemotherapy and radiation therapy, and patients exclusively treated with targeted drug therapy (e.g., monoclonal antibodies and tyrosine kinase inhibitor). The antiemetic agents used for prophylaxis were evaluated as to the therapeutic class and dose. We analysed only the use of intravenous antiemetics prescribed in the chemotherapy performed in the hospital. The guideline used to assess the appropriateness of the prescriptions was the recommendation defined by ASCO in 2011. ${ }^{(2)}$

The following variables were investigated with respect to adherence to the guideline: gender; age; solid tumors (including non-small cell lung carcinoma, breast, ovary, colon, cervix, undefined primary site, bladder and pancreas); hematological tumors (including multiple myeloma, non-Hodgkin's lymphomas and leukemias); payer (private or health plan); chemotherapy regimen, prescriber age, emetogenic potential and intent of chemotherapy (adjuvant, neoadjuvant, curative or palliative).

Categorical data were expressed as a percentage. To evaluate correlations between categorical variables, we used the $\chi^{2}$ test or the Fisher's exact test. Each variable was analyzed in univariate model and those which attained a level of significance $\leq 0.2$ were analyzed in the multivariate model. A result was considered statistically significant when $\mathrm{p} \leq 0.05$.

This project was approved by the Research Ethics Committee of the Hospital Israelita Albert Einstein (number 567,613, on March 25th, 2014, CAAE: 25697213.8.0000. 0071), and it was considered exempt from Informed Consent requirements because this was a retrospective and epidemiological study. The data used were historically recorded in databases, with no manipulation of personal information, nominal identification of patients or experiment with human beings, therefore no individual risk was involved.

\section{RESULTS}

Between January and November 2013, 208 prescriptions for 186 patients were evaluated. Of these, 139 prescriptions of chemotherapy for 105 patients met the inclusion criteria. A total of $51 \%$ of patients were male. The median age of patients was 56 years (19-89 years). Solid tumors were the most common neoplasms (56\%); among these, non-small cell lung cancer (16\%), breast cancer $(14 \%)$ and colon cancer $(6.5 \%)$ were the most frequent, whereas non-Hodgkin's lymphoma was the most common hematologic malignancy (13.5\%). As to the treatment, $43 \%$ had moderate emetogenic potential, $48 \%$ had palliative intent and $84 \%$ were funded by health plans (Table 1).

Regarding protocol adherence, 78\% (109/139) were in disagreement with the 2011 ASCO guidelines. ${ }^{(2)}$ The 
Table 1. Characteristics of patients and treatments

\begin{tabular}{|c|c|}
\hline Patients & n (\%) \\
\hline \multicolumn{2}{|l|}{ Age, years } \\
\hline$\geq 65$ & $41(29.5)$ \\
\hline$<65$ & $98(70.5)$ \\
\hline Median (interval) & $56(19-89)$ \\
\hline \multicolumn{2}{|l|}{ Gender } \\
\hline Female & $68(49)$ \\
\hline Male & $71(51)$ \\
\hline \multicolumn{2}{|l|}{ Neoplasms } \\
\hline \multicolumn{2}{|l|}{ Solid } \\
\hline NSCLC & $22(16)$ \\
\hline Breast & $20(14)$ \\
\hline Colon & $9(6.5)$ \\
\hline Ovary & $6(4.5)$ \\
\hline Head/neck & $6(4.5)$ \\
\hline Bladder & $5(3.5)$ \\
\hline Unknown primary site & $5(3.5)$ \\
\hline Pancreas & $5(3.5)$ \\
\hline \multicolumn{2}{|l|}{ Hematological } \\
\hline NHL & $19(13.5)$ \\
\hline Leukemia & $8(6)$ \\
\hline Multiple myeloma & $7(5)$ \\
\hline Other & $27(19.5)$ \\
\hline \multicolumn{2}{|l|}{ Treatment } \\
\hline \multicolumn{2}{|l|}{ Payer } \\
\hline Health plan & $117(84)$ \\
\hline Private & $22(16)$ \\
\hline \multicolumn{2}{|l|}{ Intent of chemotherapy } \\
\hline Neoadjuvant & $10(7)$ \\
\hline Adjuvant & $24(17)$ \\
\hline Curative & $39(28)$ \\
\hline Palliative & $66(48)$ \\
\hline \multicolumn{2}{|l|}{ Emetogenic potential } \\
\hline High & $47(34)$ \\
\hline Moderate & $60(43)$ \\
\hline Low & $26(19)$ \\
\hline Minimal & $6(4)$ \\
\hline
\end{tabular}

main reason for non-adherence was prescribing medications (dexamethasone, 5-HT3 and NK-1 antagonists) in higher doses than those recommended for all emetogenic levels (minimal, low, moderate or high), i.e., in 44\% (48/109) of cases. The medication most commonly prescribed above the recommended dose was dexamethasone, i.e., in $81 \%$ (39/48) of cases. Approximately $30 \%$ of the prescriptions had double disagreement (association of two discordances), and the most common combination was higher doses of dexamethasone and indiscriminate use of 5-HT3 antagonist, found in 35\% (11/31) of cases (Table 2).
Table 2. Reasons for non-adherence to the protocol of the American Society of Clinical Oncology

\begin{tabular}{lc}
\hline & $\begin{array}{c}\text { Results compared with ASCO* protocol } \\
\mathbf{n}(\%)\end{array}$ \\
\hline Non-adherence to ASCO protocol & $109(78)$ \\
Reason for non-adherence & \\
Greater number of drugs & $6(5)$ \\
Fewer drugs & $12(11)$ \\
Higher dose & $48(44)$ \\
Lower dose & $12(11)$ \\
Double discordance & $31(29)$ \\
${ }^{*}$ ASCO: American Society of Clinical Oncology.2. Of a total of 139 prescriptions, $109(78 \%)$ did not follow the protocol.
\end{tabular}

Of all prescriptions, 47 contained drug prescription errors (insufficient or excessive doses), and the most common scenarios were indiscriminate use of 5-HT3 antagonist $(16 / 47 ; 34 \%)$ for low emetogenic potential regimens, and NK-1 antagonist $(7 / 47 ; 15 \%)$ for moderate emetogenic potential regimens.

\section{Factors associated with non-adherence to guidelines}

In univariate analysis, age ( $<$ or $\geq 65$ years), gender, prescriber age ( $<$ or $\geq 45$ years), and payer (health plan or private) had no impact on adherence to protocol. However, treatment of haematological tumors $(36 \%$ versus $15 \% ; \mathrm{p}=0.005)$, high-emetogenic potential treatments ( $34 \%$ versus $15 \%$; $\mathrm{p}=0.013)$, and treatment with two or more chemotherapeutic agents $(26 \%$ versus $9 \% ; \mathrm{p}=0.05$ ) were associated with higher rates of adherence to protocol.

Treatments that included taxanes $(0 \%$ versus $25 \%$; $\mathrm{p}=0.02$ ) had lower adherence rate (Table 3). There was no statistically significant association between prescribing cisplatin and adherence to the ASCO protocol $(\mathrm{p}=0.27)$.

Table 3. Correlation of factors and appropriateness of the Brazilian Protocol and the American Society of Clinical Oncology protocol - univariate and multivariate analysis

\begin{tabular}{|c|c|c|c|c|}
\hline Variables & $\begin{array}{c}\text { Univariate } \\
\text { analysis } \\
\text { OR (95\% Cl) }\end{array}$ & $\underset{\text { value* }}{p}$ & $\begin{array}{c}\begin{array}{c}\text { Multivariate } \\
\text { analysis }\end{array} \\
\text { OR (95\% Cl) }\end{array}$ & $\begin{array}{c}\mathbf{p} \\
\text { value* }^{*}\end{array}$ \\
\hline Age, years $(<65, \geq 65)$ & $1.52(0.65-3.58)$ & 0.36 & - & - \\
\hline Sex (male, female) & - & 0.15 & - & 0.9 \\
\hline $\begin{array}{l}\text { Type of cancer (breast } \\
\text { cancer, other) }\end{array}$ & $0.36(0.08-1.65)$ & 0.24 & $0.57(0.09-3.42)$ & 0.55 \\
\hline $\begin{array}{l}\text { Prescriber age, years } \\
(\geq 45,<45)\end{array}$ & - & 0.6 & - & - \\
\hline Agents, $n(1, \geq 2)$ & $0.27(0.08-0.99)$ & 0.05 & $0.36(0.096-1.36)$ & 0.13 \\
\hline $\begin{array}{l}\text { Emetogenic risk } \\
\text { (high, other) }\end{array}$ & $2.87(1.25-6.59)$ & 0.015 & $2.36(0.99-5.66)$ & 0.05 \\
\hline $\begin{array}{l}\text { Paclitaxel based } \\
\text { chemotherapy (yes, no) }\end{array}$ & $0.0(0-)$ & 0.02 & $0.0(0-)$ & 0.98 \\
\hline
\end{tabular}


In multivariate analysis, the only variable that tended to significantly associate with emesis protocol adherence was high emetogenic potential chemotherapy $(p=0.05)$. Other variables considered significant in the univariate analysis were not determinant of guideline adherence or non-adherence after the multivariate analysis (Table 3).

\section{DISCUSSION}

The nausea and vomiting control depends on several factors, with emphasis on the underlying disease (involvement of the gastrointestinal tract), the classes of chemotherapeutic agents and the individual predisposition of each patient. To optimize the management of these side effects, several studies are investigating the triggering mechanisms, the emetogenic potential of each neoplastic agent, and the best strategy for the prevention of emesis.

For this purpose, cancer and palliative care organizations worldwide designed guidelines to indicate the most appropriate antiemetic regimen ${ }^{(2,6,7)}$ for each antineoplastic agent, alone or in combination, and thereby facilitate the management of cancer patients, based on the best scientific evidence.

This study used the ASCO guideline ${ }^{(2)}$ to assess adherence of oncologists to the recommended procedures. Whereas this information is widely available, we found that adherence to guidelines was low (22\%). A European study, which considered only moderate and high emetogenic potential regimens, found an adherence rate of $55 \%$, i.e., higher than ours. ${ }^{(8)}$

This difference may be due to the inclusion of minimum and low potential emetogenic regimens in our analysis $(32 / 139 ; 23 \%)$ and the fact that only high emetogenic potential regimens tended to associate with adherence in multivariate analysis $(\mathrm{p}=0.05)$. Other studies showed adherence rates to antiemetic guidelines ranging from $3-42 \%{ }^{(8-12)}$

Guideline adherence rates generally also vary within each medical specialty. ${ }^{(13)}$ According to a British study, $70 \%$ of cardiologists and $25 \%$ of orthopedic surgeons adhere to protocols. The study did not specifically mention the adherence rate of oncologists. ${ }^{(13)}$ This same study discussed some points that may hinder adherence, as a payment system based on volume rather than performance; the technological barrier, which is still true for some professionals, hindering access to protocols; cultural factors of physicians who mainly relies on personal experience to determine their clinical practice; and finally, the limitations of some guidelines, which have little procedural flexibility and do not reflect the complexity of the real world. ${ }^{(13)}$

The main reason for non-adherence to guidelines in this study was the prescription of higher doses of medication (44\%). We also observed that drug prescription errors occurred in $34 \%(47 / 139)$ of the prescriptions, more often the indiscriminate use of 5-HT3 antagonist for low emetogenic potential regimens, and NK-1 antagonist for moderate emetogenic potential regimens.

The use of more than the recommended drug has been shown in other studies, such as Burmeister et al., ${ }^{(9)}$ wherein $72 \%$ of patients undergoing low emetogenic risk chemotherapy received serotonin antagonists and $24 \%$ of patients receiving moderate emetogenic potential treatment used NK-1 antagonist. ${ }^{(9)}$

The use of excessive doses or number of pharmacological agents renders the treatment more expensive and does not bring benefits in controlling symptoms. It is estimated that $30 \%$ of the money invested in health could be saved, without reducing the quality of the assistance offered, if there was adherence to medical guidelines. ${ }^{(13)}$

In 2013, ASCO published a list of five important practices in oncology, which contemplated the abuse or misuse of tests and/or procedures that offer little benefit and may even be harmful to patients. ${ }^{(5)}$ One of the points discussed in this list is the use of antiemetics indicated for high emetogenic potential chemotherapies in low or moderate emetogenic potential regimens, accurately reflecting the main reason for non-adherence in our study: over-medication (dose and/or number of agents).

We believe that, from the above results, nausea and vomiting are common side effects of chemotherapy and, due to the inconvenience they cause in patients, doctors tend to use all available resources in order to preserve the quality of life and ensure success of the cancer treatment.

This study has limitations because this was a retrospective analysis based on the experience of a single institution. We do not intend to define the clinical practice in our country in absolute terms, but our results are consistent with literature data, and altogether demonstrate that much can be done to bring the clinical practice closer to evidence-based medicine.

The creation of incentive mechanisms, and checking adherence to protocols can be strategies for continuous improvement in health care. Measures such as continuing medical education, with emphasis on the management of nausea and vomiting induced by chemotherapy 
regimens of moderate and low emetogenic risk, professional assessments for quality and performance factors, and the creation of computer programs that generate reminders when there is disagreement between the prescription and the recommendations of medical organizations should be encouraged in order to improve adherence to guidelines.

\section{CONCLUSION}

Adherence to the antiemetic prophylaxis guidelines of the American Society of Clinical Oncology was low in the first cycle of antineoplastic chemotherapy. The medication most commonly prescribed in inadequate doses was dexamethasone. The only variable that tended to a significant association with adherence to the emesis protocol in multivariate analysis was high emetogenic potential chemotherapy.

\section{ACKNOWLEDGEMENTS}

We thank the nurse Alessandra Cristina Mansur and the administrative technician Jacilene Marques de Morais, of the chemotherapy outpatient clinic of the Hospital Israelita Albert Einstein, for their help in assessing the records of the patients treated at the institution.

\section{REFERENCES}

1. Hesketh PJ. Chemotherapy-induced nausea and vomiting. N Engl J Med 2008; 358(23):2482-94. Review.

2. Basch E, Prestrud AA, Hesketh PJ, Kris MG, Feyer PC, Somerfield MR, Chesney M, Clark-Snow RA, Flaherty AM, Freundlich B, Morrow G, Rao KV, Schwartz RN, Lyman GH; American Society of Clinical Oncology. Antiemetics: American Society of Clinical Oncology clinical practice guideline update. J Clin Oncol. 2011;29(31):4189-98. Review. Erratum in: J Clin Oncol. 2014;32(19):2117.
3. Hesketh PJ, Kris MG, Grunberg SM, Beck T, Hainsworth JD, Harker G, et al. Proposal for classifying the acute emetogenicity of cancer chemotherapy. J Clin Oncol. 1997;15(1):103-9. Review.

4. Grunberg SM, Warr D, Gralla RJ, Rapoport BL, Hesketh PJ, Jordan K, et al. Evaluation of new antiemetic agents and definition of antineoplastic agent emetogenicity--state of the art. Support Care Cancer. 2011;19 Suppl 1:S43-7. Review.

5. Schnipper LE, Lyman GH, Blayney DW, Hoverman JR, Raghavan D, Wollins DS et al. American Society of Clinical Oncology 2013 top five list in oncology. J Clinl Oncol. 2013;31(34):4362-70.

6. Roila F, Herrstedt J, Aapro M, Gralla RJ, Einhorn LH, Ballatori E, Bria E, ClarkSnow RA, Espersen BT, Feyer P, Grunberg SM, Hesketh PJ, Jordan K, Kris MG, Maranzano E, Molassiotis A, Morrow G, Olver I, Rapoport BL, Rittenberg C, Saito M, Tonato M, Warr D; ESMO/MASCC Guidelines Working Group. Guideline update for MASCC and ESMO in the prevention of chemotherapy-and radiotherapy-induced nausea and vomiting: results of the Perugia consensus conference. Ann Oncol. 2010;21 Suppl 5:v232-43. Review.

7. Stefani SD, Brum C. Uso de antieméticos. Rev Bras Cuidados Paliativos. 2011: (3):5-11.

8. Aapro M, Molassiotis A, Dicato M, Peláez I, Rodríguez-Lescure Á, Pastorelli D, Ma L, Burke T, Gu A, Gascon P, Roila F; PEER investigators. The effect of guideline-consistent antiemetic therapy on chemotherapy-induced nausea and vomiting (CINV): the Pan European Emesis Registry (PEER). Ann Oncol. 2012;23(8):1986-92.

9. Burmeister H, Aebi S, Studer C, Fey MF, Gautschi O. Adherence to ESMO clinical recommendations for prophylaxis of chemotherapy-induced nausea and vomiting. Support Care Cancer. 2012;20(1):141-7.

10. Gomez DR, Liao KP, Giordano S, Nguyen H, Smith BD, Elting LS. Adherence to national guidelines for antiemesis prophylaxis in patients undergoing chemotherapy for lung cancer. Cancer. 2013;119(7):1428-36

11. Chan A, Low XH, Yap KY. Assessment of the relationship between adherence with antiemetic drug therapy and control of nausea and vomiting in breast cancer patients receiving anthracycline-based chemotherapy. J Manag Care Pharm. 2012;18(5):385-94.

12. Koch S, Wein A, Siebler J, Boxberger F, Neurath MF, Harich HD, et al. Antiemetic prophylaxis and frequency of chemotherapy-induced nausea and vomiting in palliative first-line treatment of colorectal cancer patients: the Northern Bavarian IVOPAK I Project. Support Care Cancer. 2013;21 (9):2395-402.

13. Kenefick H, Lee J, Fleishman V. Barriers to guidelines adherence. Improving physician adherence to clinical practice guidelines: barriers and strategies for change. Cambridge: New England Healthcare Institute; 2008. 